\title{
BMJ Open Cross-sectional observational study of epidemiology of COVID-19 and clinical outcomes of hospitalised patients in North West London during March and April 2020
}

Guduru Gopal Rao (D) , ${ }^{1}$ Alexander Allen, ${ }^{2}$ Padmasayee Papineni, ${ }^{1}$ Liyang Wang, ${ }^{1}$ Charlotte Anderson, ${ }^{2}$ Alastair McGregor, ${ }^{1}$ Ashley Whittington, ${ }^{1}$ Laurence John, ${ }^{1}$ Miriam Harris, ${ }^{1}$ Stephen Hiles, ${ }^{1}$ Thomas Nicholas, ${ }^{1}$ Katherine Adams, ${ }^{1}$ Ayesha Akbar, ${ }^{1}$ Paula Blomquist, ${ }^{2}$ Valerie Decraene, ${ }^{2}$ Bharat Patel, ${ }^{2}$ Rohini Manuel, ${ }^{2}$ Yimmy Chow, ${ }^{2}$ Martin Kuper, ${ }^{1}$ London North West Healthcare Trust COVID-19 Research Group ${ }^{1}$

To cite: Gopal Rao G, Allen A, Papineni P, et al. Crosssectional observational study of epidemiology of COVID-19 and clinical outcomes of hospitalised patients in North West London during March and April 2020. BMJ Open 2021;11:e044384. doi:10.1136/ bmjopen-2020-044384

- Prepublication history and additional material for this paper is available online. To view these files, please visit the journal online (http://dx.doi.org/10. 1136/bmjopen-2020-044384).

Received 01 September 2020 Revised 22 December 2020 Accepted 13 January 2021

Check for updates

(c) Author(s) (or their employer(s)) 2021. Re-use permitted under CC BY-NC. No commercial re-use. See rights and permissions. Published by BMJ.

${ }^{1}$ Departments of Microbiology, Infectious Diseases, Emergency, Research and Development and Corporate Affairs, London North West University Healthcare NHS Trust, London, UK

${ }^{2}$ Field Epidemiology and Health Protection Units, Public Health England, London, UK

Correspondence to Dr Guduru Gopal Rao; ggopalrao@nhs.net

\section{ABSTRACT}

Objective The aim of this paper is to describe evolution, epidemiology and clinical outcomes of COVID-19 in subjects tested at or admitted to hospitals in North West London.

Design Observational cohort study.

Setting London North West Healthcare NHS Trust (LNWH). Participants Patients tested and/or admitted for COVID-19 at LNWH during March and April 2020

Main outcome measures Descriptive and analytical epidemiology of demographic and clinical outcomes (intensive care unit (ICU) admission, mechanical ventilation and mortality) of those who tested positive for COVID-19.

Results The outbreak began in the first week of March 2020 and reached a peak by the end of March and first week of April. In the study period, 6183 tests were performed in on 4981 people. Of the 2086 laboratory confirmed COVID-19 cases, 1901 were admitted to hospital. Older age group, men and those of black or Asian minority ethnic (BAME) group were predominantly affected $(p<0.05)$. These groups also had more severe infection resulting in ICU admission and need for mechanical ventilation $(p<0.05)$. However, in a multivariate analysis, only increasing age was independently associated with increased risk of death $(p<0.05)$. Mortality rate was $26.9 \%$ in hospitalised patients.

Conclusion The findings confirm that men, BAME and older population were most commonly and severely affected groups. Only older age was independently associated with mortality.

\section{BACKGROUND}

An outbreak of severe pneumonia of unknown cause was reported by Chinese authorities in December 2019, ${ }^{1}$ and the virus responsible, SARS-CoV-2, was reported by the WHO in January and subsequently named as COVID-19 by WHO. ${ }^{2}$
Strengths and limitations of this study

This study describes the evolution and epidemiology of COVID-19 outbreak in in a highly ethnically and socioeconomically diverse population of North West London, which was the first and most severely affected area in the UK.

- The study evaluated ethnicity and socioeconomic deprivation and their association with risk of hospital admission due to COVID-19, admission to intensive care unit, need for mechanical ventilation and death.

- Single-centre study and therefore results may not be generalisable.

- We did not explore the association between COVID19-related death and comorbidities or severity of illness at time of hospital admission.

The first UK cases of COVID-19 were confirmed on 31 January $2020 .^{3}$ In the initial stages of the outbreak, London was one of the most affected areas in the UK. Brent, Harrow and Ealing in North West London were among the first and most severely affected boroughs in London. The three boroughs have a population of one million, which is among the most diverse in the UK, with proportion of the population from black, Asian and other minority ethnic (BAME) backgrounds being $51 \%$ in Ealing, $57.8 \%$ in Harrow and $63.7 \%$ in Brent. ${ }^{4}$ These boroughs also have areas of significant deprivation. ${ }^{5}$

Northwick Park (NPH) and Ealing Hospitals $(\mathrm{EH})$ are the two acute general hospitals that primarily serve the population of the three boroughs. These hospitals have infectious diseases departments and NPH was 
the first hospital in the UK to provide community and 'drive through' COVID-19 testing facilities for symptomatic persons in the community who had travelled to or had been in contact with those who travelled to 'high risk' countries identified by the UK Government in the early stages of the outbreak in the UK. ${ }^{6-8}$ Patients with COVID-19 requiring hospitalisation were admitted to NPH and EH. The first patient with COVID-19 was admitted to NPH on 3 March 2020.

The aim of this paper is to describe the epidemiology of patients tested in or admitted to NPH and EH in the 'contain' and subsequently, 'delay' phases of COVID-19 outbreak to understand the evolution of the outbreak, demographic distribution, putative risk factors and clinical outcomes of the patients hospitalised with COVID-19 infection in the boroughs of Brent, Harrow and Ealing in London.

\section{METHODS}

This is a retrospective observational cohort study of people tested for SARS-CoV-2 at NPH and EH during the study period 1 March-30 April 2020.

\section{Patient and public participation}

Given the retrospective nature of the report, it was not appropriate or possible to involve patients or the public in the design, or conduct, or reporting, or dissemination plans of our research. The findings of this study will not be disseminated to individual patients but will be disseminated to the public through publication in peer reviewed journals

\section{Data collection and management}

Information regarding people tested for SARS-CoV-2 was obtained from the laboratory information system (Winpath, Isoft). Information regarding demographics and clinical outcomes was obtained from the hospitals' information systems including the patient administrative system, Symphony clinical management system (EMISHealth, UK) used in emergency departments at NPH and EH and Epro (UK), an electronic patient record software used in the hospitals to record clinical progress and outcomes.

Demographic information collected included age, sex, ethnicity and postcode of patient's residence. The five ethnic group categories used in this paper are: white; mixed/multiple ethnic groups; Asian/Asian British; black/African/Caribbean/black British; and Other ethnic group. These categories are derived from the harmonised classification of ethnic groups-white includes British, Irish and any other white background; Asian includes Indian, Pakistani, Bangladeshi and any other South Asian background such as Sri Lankan; black includes Caribbean, African and any other black background; Other includes any other ethnic group, including Chinese, Filipino and Arab. ${ }^{4}$ The postcode was used to derive English Index of Deprivation for 2019. ${ }^{9}$
Clinical outcome variables were limited to admission to the intensive care unit (ICU), need for mechanical ventilation and in-hospital mortality during the study period. Two datasets were created for analysis: a test-level dataset and a patient-level dataset, with results de-duplicated on National Health Service (NHS) number or hospital number. In the patient-level dataset, persons were classified as cases, non-cases, and unknown-status according to total available SARS-CoV-2 testing history. Cases were persons with at least one positive SARS-CoV-2 test, and date of positivity was based on date of first positive test.

\section{Microbiology}

Pooled nose and throat, nasopharyngeal, sputum or bronchoalveolar lavage specimens were processed for detection of using reverse transcriptase PCR at the Public Health England (PHE), Colindale, London (1 March-13 March 2020) and The Doctors Laboratory, London (14 March-30 April 2020) using methods verified by the PHE. $^{10}$

\section{Data analysis and statistical methods}

Laboratory data were analysed to produce an epidemic curve for the number of positive tests on a day-by-day basis. Demographic and clinical outcomes were described by person characteristic among those who tested positive.

Statistical analysis was carried out for the variables age, sex, ethnic group and deprivation quintile, on the odds of being a case, and on outcome and clinical severity. The outcome data were limited to the 23 June 2020.

The analysis of the tests was split across the contain (up to 12 March 2020, inclusive) and delay phases (after 12 March 2020), as these represent two different testing strategies. ${ }^{7}$ During the contain phase, people reporting travel to a high-risk area or contact with a confirmed case and symptoms of cough, fever or shortness of breath were tested. During the delay phase, only those presenting with symptoms at a hospital setting were tested, or those within residential or care home outbreak investigations.

Difference in median age was tested using the Wilcox Rank Sum Test, and differences in proportion were tested using the $\chi^{2}$ test. ORs and CIs were calculated, and $\mathrm{p}$ values were generated using Wald Tests. Tests for linear trend were analysed by comparing the model with age as a continuous variable and as a categorical variable using Likelihood Ratio Tests. Tests for interaction between each variable in the univariate and multivariate analysis were carried out using Likelihood Ratio Tests.

\section{RESULTS}

\section{Testing trends}

The distribution of all tests for SARS-CoV-2 over time is shown in figure 1 . This shows that peak testing took place on 11 March (171 tests; 14\% positive), Subsequently, the daily number of tests performed dropped, before increasing to a second peak on 23 March with 165 tests, of which $50 \%$ were positive. The overall positivity rate 


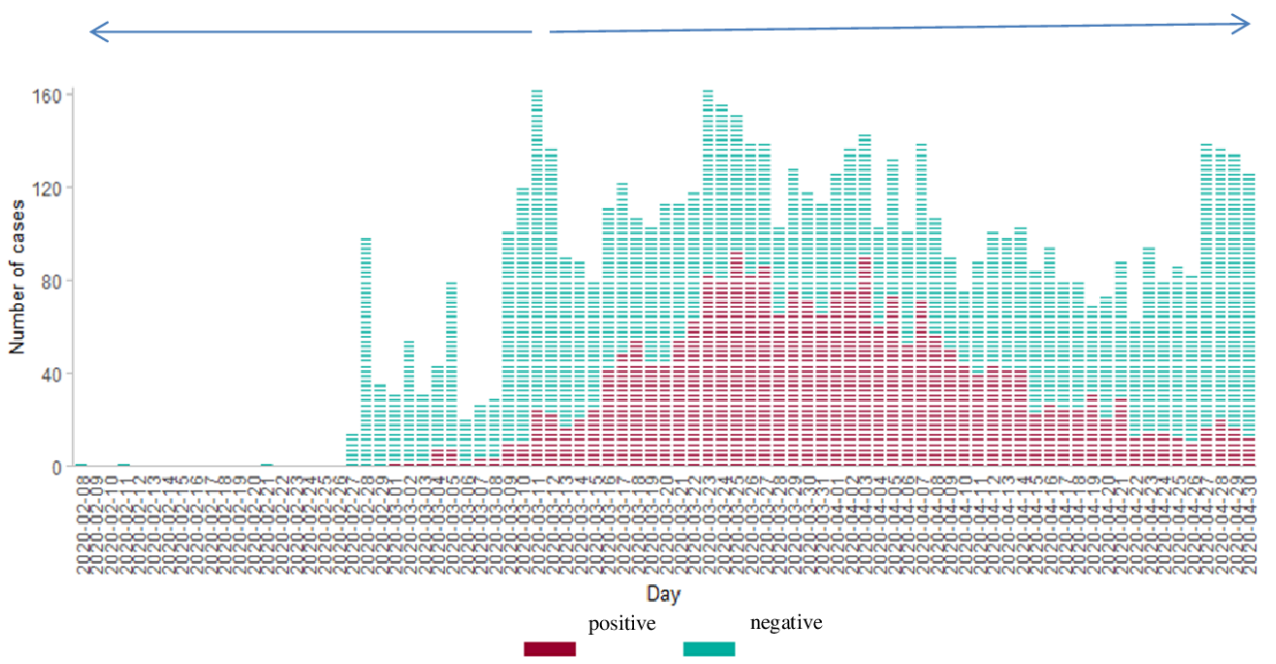

Figure 1 Distribution of all known results by date.

during the contain phase was $7.7 \%(53 / 686)$ and for the delay phase was $41.1 \%$ (2259/5497).

The distribution of people who tested positive for SARS-CoV-2 over time is shown in online supplemental figure 1.

\section{Demographic characteristics of persons tested and COVID-19} cases

In the study period unique 6183 tests were performed on samples from 4981 people. The median age of all people tested was 61 years (IQR from 42 to 79 years), and $44.2 \%$ (2013/4450) were women. Two thousand eighty-six laboratory confirmed COVID-19 cases were identified. Data completeness in the patient-level dataset was $100 \%$ for age, $92 \%$ for sex, $98 \%$ for postcode and $74 \%$ for ethnicity. Overall, cases were more likely to be older and men. Of the 4717 people tested with information on ethnicity, the most common ethnic groups were white $(1603,39.5 \%)$ and Asian (1289, 31.4\%). Age and sex distribution of those who tested positive is shown in figure 2. Positive tests were highest among those of black (52\%) and Asian (51\%) ethnicity. Among 4881 persons tested for COVID-19 with a valid postcode of residence, $86 \%$ were residents of the boroughs covered by the hospitals' usual catchment area (Brent, Ealing or Harrow) and 14\% were residents outside this area. Densities of distribution of number of persons tested and those positive within the boroughs are

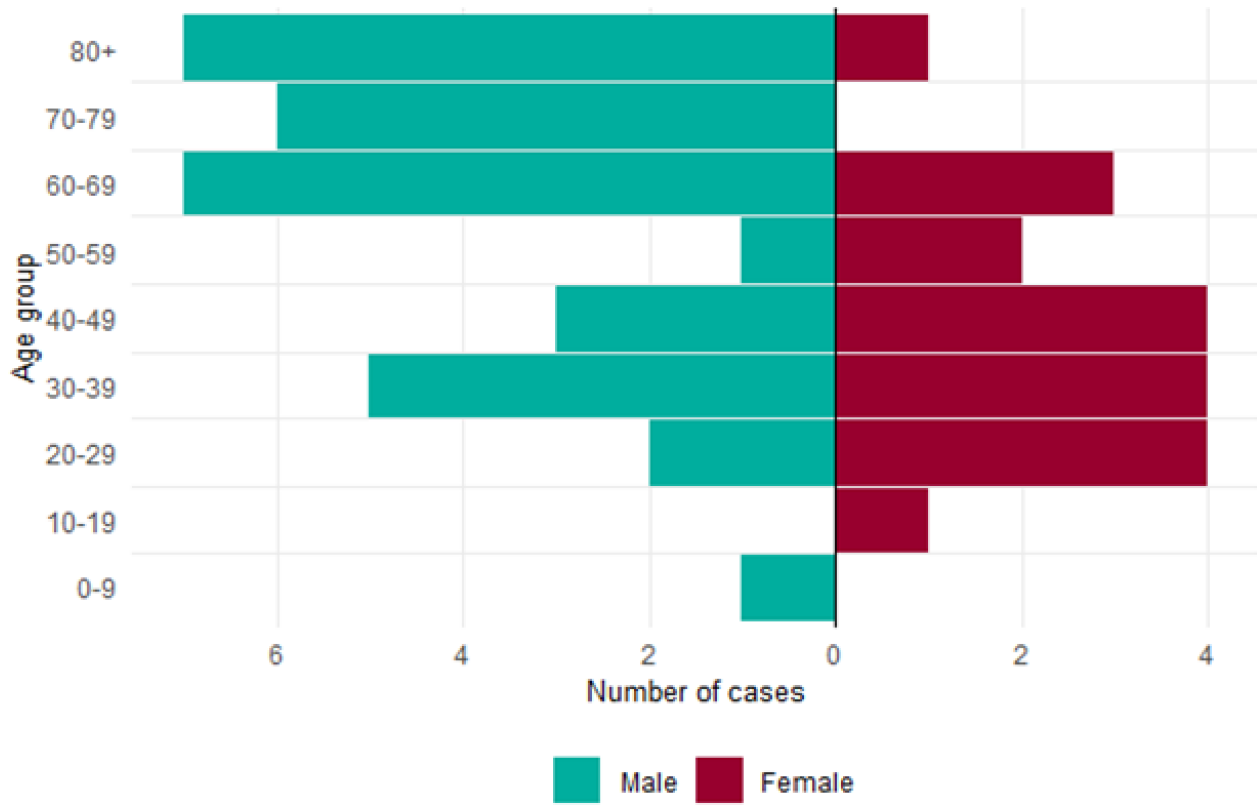

Figure 2 Age and sex distribution of people testing positive. 
Only Lower-layer Super Output Areas (LSOAs) within LNWH catchment area (Harrow,

Brent, and Ealing boroughs) and in neighboring Hillingdon borough shown

A) Persons tested for COVID-19 at LNWH

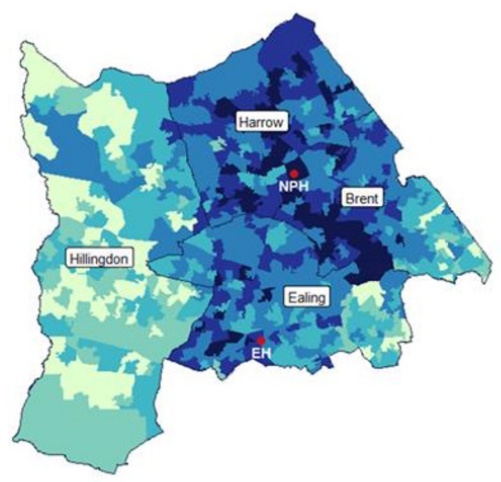

B) Persons diagnosed with COVID-19 by LNWH

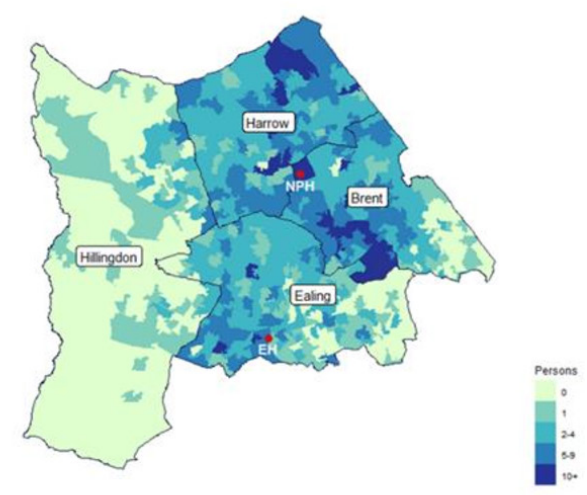

Figure 3 Map of numbers of (A) persons tested and (B) persons diagnosed with COVID-19 by London North West Healthcare NHS Trust (LNWH) up to 30 April 2020, by residence.

shown figure 3. The proportion of persons who tested positive was lowest in Ealing (38.4\%) and highest in Brent $(46.3 \%)$. Among each ethnic group tested with a known result, the positivity was highest among those of black (22.2\%) and Asian (7.9\%) ethnicity.

During the contain phase, the median age of all individuals tested was 37 years (IQR from 28 to 57 years), and $48.7 \%(336 / 689)$ were women. Cases were more likely to be older and men. The most common ethnic groups among people tested, were white $(207,36.7 \%)$ and Asian $(127,37.9 \%)$. Among each ethnic group tested with a known result, the positivity was highest among those of black $(22.2 \%)$ and Asian $(7.9 \%)$ ethnicity.

During the delay phase, the median age of all people tested was 65 years (IQR 33 years), and 1689 (43.2\%) were women. Cases were more likely to be older and men. Among people with information on ethnicity, the most common ethnic groups were white $(1396,32.4 \%)$ and Asian (1162, 27.0\%). The positivity was highest among those of black (54\%) and Asian (56\%) ethnicity. In this phase, $828(84 \%)$ patients who tested positive were admitted to the hospital.

In a univariate analysis, in both contain and delay phases male sex and increasing age were associated with increased odds of being a case. There was no evidence of an association between Asian ethnicity and testing positive during the contain phase, but in the delay phase those of Asian ethnicity had increased odds of being a case (OR 1.77 (95\% CIs 1.51 to 2.06)). There was weak evidence that black ethnicity was associated with testing positive during containment, and stronger evidence during delay phase (OR 1.62 (95\% CIs 1.30 to 2.01)) (table 1).

In a multivariate analysis, after controlling for the other demographic variables, increasing age and male sex were still associated with an increased odd of testing positive in both phases. In the delay phase, the odds of being a case and of Asian and black ethnicity increased after adjusting for the other demographic variables (OR 1.98; 95\% CI 1.68 to 2.34$)$ and (1.82; $95 \%$ CI 1.45 to 2.29$)$ indicating a degree of positive confounding: cases in these ethnicities were on average younger than those of white ethnicity. However, there was no evidence of interaction for each pair of variables (table 2).

\section{Clinical outcomes of cases}

The flow chart of number tested, number positive and clinical outcomes is shown in figure 4 .

Outcome information was available for 1901 patients with confirmed COVID-19 infection. This is shown in online supplemental table 1 . Univariate and multivariate analysis of the characteristics associated with clinical outcomes and severity is presented in table 3 , online supplemental tables 1 and 2. The analysis is limited to the delay phase as the numbers of events were small in the containment phase.

The overall death rate was $26.9 \%(510 / 1901)$. Odds of death increased significantly with age. Each year of increasing age increased the odds of death (OR 1.07 $(1.06-1.07))$. The death rate was highest $(254 / 546$, $46.5 \%$ ) in the over 80 years age group. However, gender, ethnic group, level of deprivation or borough of residence were not significantly associated with increased likelihood of death (table 3). Clinical outcome of 12 patients who were transferred to other hospitals in London was not available at the time of writing.

The median period between the SARS-CoV-2 positive swab result and discharge from the hospital was 7.2 days (range $0-60$ days). The median period between SARS-CoV-2 positive swab result and death was 6.3 days (range $0-45$ days).

Male sex (OR 2.29 (1.57 to 3.35)) and Asian (OR 3.38 (1.88 to 6.06$)$ ) and black (OR 4.77 (2.47 to 9.23)) ethnicity were associated with increased odds of ICU admission (online supplemental table 1). Male sex was 
Table 1 Univariate analysis: association of demographic features and testing positive in the delay phase ( $\mathrm{n}=2086$ cases)

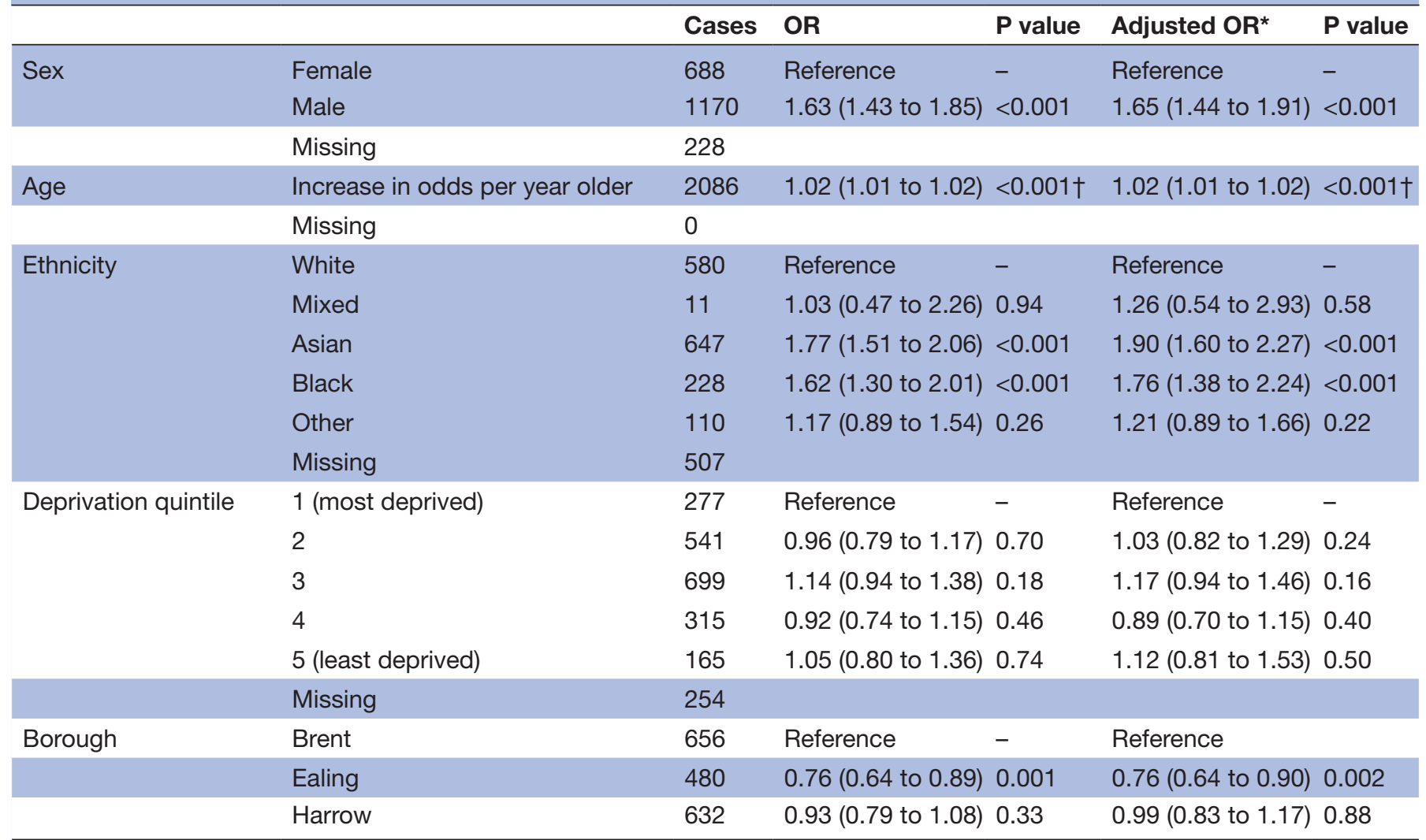

${ }^{*}$ Adjusted for every other variable in the table.

†Test for linear trend $p<0.001$.

associated with an increased need for mechanical ventilation (OR 2.55 (1.51 to 4.93)), as was Asian (OR 5.13 (2.14 to 12.30$)$ ) and black ethnicity (OR 3.97 (1.44 to 10.96)) (online supplemental table 2).

\section{DISCUSSION}

In this paper, we have presented the results of the epidemiological investigation of COVID-19 infection in three boroughs of London which were the earliest and most severely affected. The reason for this is unclear and should be investigated further. During the contain phase, the PHE guidelines recommended that only those reporting symptoms of COVID-19 infection and a history of travel to a high-risk country/area or contact with a known case of COVID-19 should be tested. ${ }^{8}$ Relatively large numbers of people were tested daily during the contain phase (up until 12 March), through community and drive-through testing services and the accident and emergency department of the hospitals. ${ }^{67}$ Suspected patients and contacts were referred to NPH and EH because of the presence of infectious diseases units in these hospitals. Of those tested, most were young adults (median age 37 years), and most often of white or Asian ethnicity, which represents the demographics of the local resident population who had travel or contact history. At this stage of the evolution of the outbreak, only $8 \%$ tested positive for SARS-Cov-2.
Being men, older and of black ethnicity (compared with white) was associated with increased odds of testing positive. Very few of those who tested positive had an ICU admission and only one person required mechanical ventilation. Thus, the severity of infection in those affected in the containment phase appeared to be relatively mild. During this phase, deaths also were relatively fewer $(6 / 51$, $11.7 \%$ ), likely due to the younger age group tested and less severe patients were admitted to the hospital. It is, however, possible that deaths in the community due to COVID-19 may have been missed as the patients would not have been tested unless the patients met the case definition at the time.

During the delay phase (after 12 March 2020), all new and current inpatients with COVID-19-compatible symptoms were tested. These tended to be older individuals (median 68 years old), and of white or Asian ethnicity. Half of those tested were positive: from our analysis, being men, older and of black ethnicity were again associated with increased odds of testing positive. The association of COVID-19 infection with male sex, older age and of black (African and Caribbean) or Asian ethnicity, particularly of South Asian origin (Indian, Pakistani, Bangladeshi) is now well recognised in the UK. ${ }^{11}$

In our study, ICU admission and mechanical ventilation were commoner in older patients (up to the age of 69 
Table 2 Hospital outcomes for people testing positive for SARS-CoV-2 in delay phase where outcome data was available ( $n=1901$ cases)

\begin{tabular}{|c|c|c|c|c|c|c|c|c|}
\hline & & Total cases & No. ITU admissions & $\%$ & Mechanical ventilation & $\%$ & Number of deaths & $\%$ \\
\hline Overall & & 1901 & 219 & 11.7 & 120 & 6.5 & 510 & 26.8 \\
\hline \multirow[t]{3}{*}{ Sex } & Female & 699 & 44 & 6.3 & 23 & 3.3 & 191 & 27.3 \\
\hline & Male & 1193 & 167 & 14.0 & 95 & 8.0 & 318 & 26.6 \\
\hline & Missing & 10 & 1 & & 2 & & 1 & \\
\hline \multirow[t]{10}{*}{ Age } & $0-9$ & 9 & 0 & 0 & 0 & 0 & 0 & 0 \\
\hline & $10-19$ & 5 & 1 & 20.0 & 1 & 20.0 & 0 & 0 \\
\hline & 20-29 & 39 & 5 & 13.5 & 2 & 5.4 & 0 & 0 \\
\hline & 30-39 & 88 & 11 & 13.1 & 10 & 11.9 & 1 & 1.1 \\
\hline & $40-49$ & 168 & 31 & 18.9 & 15 & 9.1 & 13 & 7.7 \\
\hline & $50-59$ & 303 & 63 & 21.1 & 39 & 13.0 & 35 & 11.6 \\
\hline & $60-69$ & 341 & 63 & 19.2 & 37 & 11.3 & 69 & 20.2 \\
\hline & $70-79$ & 397 & 33 & 8.7 & 13 & 3.4 & 138 & 34.7 \\
\hline & $80+$ & 546 & 3 & 0.5 & 3 & 0.6 & 254 & 46.5 \\
\hline & Missing & 4 & 0 & & 0 & & 0 & \\
\hline \multirow[t]{6}{*}{ Ethnicity } & White & 514 & 18 & 3.7 & 8 & 1.6 & 166 & 32.3 \\
\hline & Mixed & 11 & 1 & 9.1 & 1 & 9.1 & 2 & 18.2 \\
\hline & Asian & 679 & 84 & 12.7 & 54 & 8.0 & 174 & 25.3 \\
\hline & Black & 237 & 40 & 17.5 & 16 & 7.0 & 61 & 25.7 \\
\hline & Other & 118 & 17 & 14.5 & 11 & 9.4 & 29 & 24.6 \\
\hline & Missing & 342 & 54 & & 30 & & 78 & \\
\hline
\end{tabular}

ITU, Intensive Treatment Unit.

years), men, and in Asian and black ethnic groups. This echoes the observations of the national intensive care audit data of patients with COVID-19. ${ }^{12}$

As determined on 23 June 2020, 7 weeks after the last patient included in this study, $26.8 \%$ of those who tested positive were known to have died, similar to other UK data. ${ }^{3}$ The odds of death were not increased in men, despite their increased risk of ICU admission and mechanical ventilation. Similarly, there were no increased odds of death across the different ethnicities, deprivation quintiles or borough of residence.

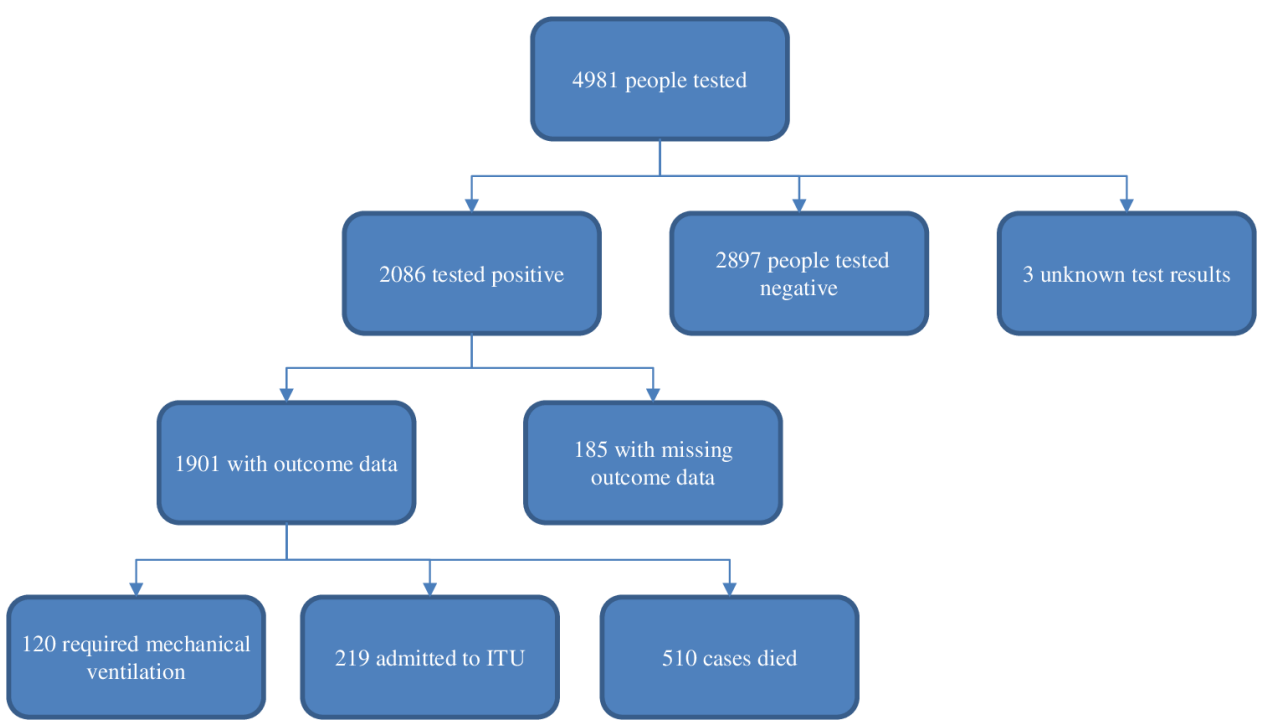

Figure 4 Flow chart of patients tested for COVID-19 and clinical outcome. 
Table 3 Univariate and multivariate analysis: association of demographic features of cases associated with deaths

\begin{tabular}{|c|c|c|c|c|c|c|}
\hline & & Deaths & Crude OR (95\% Cls) & $P$ value & $\begin{array}{l}\text { Adjusted ORs (95\% } \\
\text { Cls)* }\end{array}$ & $P$ value \\
\hline Sex & Female & 191 & Reference & & Reference & \\
\hline Age & $\begin{array}{l}\text { Increase in odds per } \\
\text { year older }\end{array}$ & 510 & 1.07 (1.06 to 1.07$)$ & $<0.001 \dagger$ & $1.06(1.06$ to 1.07$)$ & $<0.001 \dagger$ \\
\hline \multirow{3}{*}{ Ethnicity } & Asian & 174 & 0.72 (0.56 to 0.93 ) & 0.01 & 1.05 (0.79 to 1.37$)$ & 0.75 \\
\hline & Black & 61 & $0.73(0.51$ to 1.03$)$ & 0.07 & $1.13(0.78$ to 1.65$)$ & 0.51 \\
\hline & Other & 29 & $0.68(0.43$ to 1.08$)$ & 0.1 & 1.13 (0.69 to 1.87$)$ & 0.62 \\
\hline \multirow[t]{2}{*}{ Deprivation quintile } & 1 (most deprived) & 92 & Reference & & Reference & - \\
\hline & 5 (least deprived) & 66 & 1.47 (0.96 to 2.26 ) & 0.08 & 1.34 (0.83 to 2.18$)$ & 0.23 \\
\hline \multirow[t]{3}{*}{ Borough } & Brent & 116 & Reference & & Reference & - \\
\hline & Ealing & 119 & 0.95 (0.73 to 1.25$)$ & 0.72 & 1.02 (0.75 to 1.39$)$ & 0.89 \\
\hline & Harrow & 186 & $1.23(0.96$ to 1.57$)$ & 0.10 & $1.15(0.86$ to 1.152$)$ & 0.34 \\
\hline
\end{tabular}

*Adjusted for every other variable in the table.

†Test for linear trend $p<0.001$.

The PHE report into disparities and the risk and outcomes of COVID-19 found diagnosis rates were higher in deprived areas, and in black people. Increasing age, deprivation and black or Asian ethnicity had higher death rates. ${ }^{13}$ There is emerging evidence on the disproportionate impact of COVID-19 on BAME communities in the $\mathrm{USA}^{14}$ and $\mathrm{UK}^{1516}$

It is unclear why we did not observe higher rate of mortality in BAME group with COVID-19 in our hospitals despite a higher rate admission to the ICU and mechanical ventilation. A possible reason could be that our hospitals have consistently low 30-day mortality rate despite providing care for a population with high proportion of BAME and deprived groups. The latest summary hospitallevel mortality indicator (SHMI) for the year April 2019March 2020 published by NHS Digital confirms that our hospitals (London North West Healthcare Trust) have the ninth lowest mortality rate in the country. This indicator does not include COVID-19 associated deaths. However, an experimental SHMI indicator recently developed by NHS Digital also shows that our hospitals had third lowest SHMI in England even after COVID-19 associated deaths are included. ${ }^{17}$ Furthermore, in this study, the age distribution of patients of different ethnicities with COVID-19 was not identical. Over a quarter of affected patients were 80 years or older $(546 / 1901,28 \%)$ and were predominantly from white and Asian ethnic groups, with a high mortality (over 45\%). This probably explains why age but not ethnicity, deprivation and sex were associated with mortality in a multivariate analysis. Other studies have similarly found no association between increased mortality and ethnicity. ${ }^{18-20}$

While we acknowledge that the findings of our single centre study may not be generalisable, it is possible that although BAME groups may be at higher risk of infection but poor clinical outcomes in these groups may be dependent on asymmetrical access to healthcare or quality of healthcare in areas with a high prevalence of BAME population.

\section{Strengths and limitations}

The strength of this study is that it describes the evolution and epidemiology of COVID-19 outbreak in a highly ethnically and socioeconomically diverse population of North West London, which was the first and most severely affected area in the UK. The findings show that although older individuals, those belonging to BAME and socioeconomically deprived groups were at greater risk of acquiring SARS-CoV-2 and had increased risk of admission to ICU and mechanical ventilation, unlike other published studies in the UK, only increasing age was independently associated with increased mortality.

The study was limited to patients presenting to acute hospitals and did not address the entire outbreak in the community. Ethnicity was self-reported and was not stated in nearly $25 \%$ of patients. Deprivation level was derived from the postcode of residence and based on the assumptions regarding the populations living in certain postcodes. These assumptions are generally considered 
accurate at a population level but may not be at an individual level.

Our data were limited to demographics and we were unable to explore the association between COVID-19 and comorbidities such as diabetes and obesity, employment in the 'gig economy', social networks such as places of worship, racial discrimination and health inequalities and household characteristics such as multioccupancy or multigenerational living in this analysis.

Our data were limited to only composite end points such as admission to ICU and need for mechanical ventilation as surrogate markers for assessing severity. We did not evaluate the impact of comorbidities, severity of illness at time of presentation to hospital and other factors that may have contributed to death.

This analysis is limited to the epidemiology of laboratory confirmed patients with COVID-19. Patients with a clinical diagnosis of COVID-19 only were excluded. The accuracy of the results of COVID-19 tests was dependent on the methods used. ${ }^{21}$

Given that this epidemiological study of the outbreak was performed in a single organisation serving a limited geographical area, the results may not be generalisable.

Some of the patients requiring mechanical ventilation were transferred to other hospitals in London. Outcome data of a small proportion of these patients were not available at the time of writing.

\section{CONCLUSIONS}

There was a large outbreak of COVID-19 affecting the population of the boroughs of Brent, Harrow and Ealing in March and April 2020. The outbreak began in the first week of March 2020 and reached a peak at the end of March and first week of April. Older age group, men and those of black or Asian ethnic group were predominantly affected among those patients tested at the hospital facilities. The mortality rate of hospitalised patients was comparable to the national average in the UK. Our study highlights the evolution and impact of COVID-19 outbreak in one of the earliest and severely affected population in London. The findings of the study confirm that male BAME and elderly population were most commonly and severely affected groups. Targeted public health measures should be taken to prevent COVID-19 in this vulnerable population.

Acknowledgements The authors acknowledge all healthcare workers and staff of London North West University Healthcare NHS Trust who provided selfless care for the patients during the outbreak.

Collaborators London North West Healthcare Trust COVID-19 Research Group (Collaborators): Sharpe Roger, Cohen David, Tennant Rachel, Vaid Nidhi, Sahnan Kapil, Gross Jamie, Husain Tariq, Parris Victoria, Sandhu Gurjinder, Rosen Stuart, Cayley Charles, Patel Sangita, Blair Mitchel, Lewis Simon, Chita Sunder, Winn Trish, Biggin-Lamming James, Sewel Catherine, Gregory Laila, Tozer Philip, Littler Stephen.

Contributors GGR, AA, LW, CA, BP, VD: contributed to conception, literature search, figures, study design, data collection, data analysis, data interpretation, writing. $\mathrm{SH}$ TN, KA: contributed to data collection and analysis. PP, AM, AW, LJ, MH, PB, RM, YC, $A A, M K$ : contributed to literature search, data interpretation, writing, supervision.
London North West Healthcare Trust COVID-19 Research Group contributed to overall supervision and validation.

Funding The authors have not declared a specific grant for this research from any funding agency in the public, commercial or not-for-profit sectors.

Disclaimer The lead author ( $\mathrm{Dr} \mathrm{G}$ Gopal Rao) affirms that the manuscript is an honest, accurate, and transparent account of the study being reported; that no important aspects of the study have been omitted; and that any discrepancies from the study as planned have been explained.

Map disclaimer The depiction of boundaries on this map does not imply the expression of any opinion whatsoever on the part of BMJ (or any member of its group) concerning the legal status of any country, territory, jurisdiction or area or of its authorities. This map is provided without any warranty of any kind, either express or implied.

Competing interests All authors have completed the Unified Competing Interest form at www.icmje.org/coi_disclosure.pdf (available on request from the corresponding author) and declare: no support from any organisation for the submitted work; no financial relationships with any organisations that might have an interest in the submitted work in the previous three years, no other relationships or activities that could appear to have influenced the submitted work.

Patient consent for publication Not required.

Ethics approval This was a report of an epidemiological investigation of an outbreak, research ethics committee approval was not required. ${ }^{22}$ Publication of this report was approved by the London North West University Healthcare NHS Trust Research and Development oversight committee.

Provenance and peer review Not commissioned; externally peer reviewed.

Data availability statement № additional data available.

Supplemental material This content has been supplied by the author(s). It has not been vetted by BMJ Publishing Group Limited (BMJ) and may not have been peer-reviewed. Any opinions or recommendations discussed are solely those of the author(s) and are not endorsed by BMJ. BMJ disclaims all liability and responsibility arising from any reliance placed on the content. Where the content includes any translated material, BMJ does not warrant the accuracy and reliability of the translations (including but not limited to local regulations, clinical guidelines, terminology, drug names and drug dosages), and is not responsible for any error and/or omissions arising from translation and adaptation or otherwise.

Open access This is an open access article distributed in accordance with the Creative Commons Attribution Non Commercial (CC BY-NC 4.0) license, which permits others to distribute, remix, adapt, build upon this work non-commercially, and license their derivative works on different terms, provided the original work is properly cited, appropriate credit is given, any changes made indicated, and the use is non-commercial. See: http://creativecommons.org/licenses/by-nc/4.0/.

ORCID iD

Guduru Gopal Rao http://orcid.org/0000-0002-8108-4431

\section{REFERENCES}

1 Zhu N, Zhang D, Wang W, et al. A novel coronavirus from patients with pneumonia in China, 2019. N Engl J Med 2020;382:727-33.

2 WHO. Rolling updates on coronavirus disease (COVID-19), 2020. Available: https://www.who.int/emergencies/diseases/novelcoronavirus-2019/events-as-they-happen

3 Docherty AB, Harrison EM, Green CA, et al. Features of 20133 UK patients in hospital with covid-19 using the ISARIC WHO Clinical Characterisation Protocol: prospective observational cohort study. BMJ 2020;369:m1985.

4 GOV UK. Population of England and Wales. ethnicity facts and figures GOV UK, 2018. Available: https://www.ethnicity-facts-figures. service.gov.uk/uk-population-by-ethnicity/national-and-regionalpopulations/population-of-england-and-wales/latest

5 Indices of Deprivation 2019. Ward level summary measures for London April 2020, 2020. Available: https://data.london.gov.uk/ dataset/indices-of-deprivation

6 Mahase E. Coronavirus: home testing pilot launched in London to cut Hospital visits and ambulance use. BMJ 2020;368:m621.

7 Wallis G, Siracusa F, Blank M, et al. Experience of a novel community testing programme for COVID-19 in London: lessons learnt. Clin Med 2020;20:e165-9. 
8 NHS England. NHS comments on coronavirus 'drive through' testing service, 2020. Available: https://www.england.nhs.uk/2020/02/nhscomments-on-coronavirus-drive-through-testing-service

9 Ministries of Housing. Communities and development. English indices of deprivation 2019, 2020. Available: https://assets. publishing.service.gov.uk/government/uploads/system/uploads/ attachment data/file/853811/loD2019 FAQ_v4.pdf

10 NHS England. Guidance and SOP - COVID-19 virus testing in NHS laboratories, 2020. Available: https://www.ibms.org/resources/ documents/guidance-and-standard-operating-procedure-covid-19virus/

11 Public Health England. COVID-19: review of disparities in risks and outcomes, 2020. Available: https://www.gov.uk/government/ publications/covid-19-review-of-disparities-in-risks-and-outcomes

12 Intensive care national audit and research centre (ICNARC). ICNARC report on COVID-19 in critical care 17 July 2020, 2020. Available: https://www.icnarc.org/DataServices/Attachments/Download/ c0df94a2-4ec8-ea11-9127-00505601089b

13 Public Health England. Disparities in the risk and outcomes of COVID-19, 2020. Available: https://assets.publishing.service.gov.uk/ government/uploads/system/uploads/attachment_data/file/892085/ disparities_review.pdf

14 Price-Haywood EG, Burton J, Fort D, et al. Hospitalization and mortality among black patients and white patients with COVID-19. N Engl J Med Overseas Ed 2020;382:2534-43.

15 Harrison EM, Docherty AB, Barr B. Ethnicity and outcomes from COVID-19: the ISARIC CCP-UK prospective observational cohort study of hospitalised patients. 2020. https://papers.ssrn.com/sol3/ papers.cfm?abstract_id=3618215

16 Pan D, Sze S, Minhas JS, et al. The impact of ethnicity on clinical outcomes in COVID-19: a systematic review. EClinicalMedicine 2020;23:100404.

17 NHS Digital. Summary hospital-level mortality indicator (SHMI), England, April 2019 - March 2020, 2020. Available: https://app. powerbi.com/view?r=eyJrljoiMWQwMDAzZjgtYTZjZi00NjdjLWFi NWMtYTVkM2JiNTdIMTFhliwidCI6ljUwZjYwNzFmLWJiZmUtNDAx YS04ODAzLTY3Mzc00GU2MjllMilsImMiOjh9

18 Gold JAW, Wong KK, Szablewski CM, et al. Characteristics and clinical outcomes of adult patients hospitalized with COVID-19 - Georgia, March 2020. MMWR Morb Mortal Wkly Rep 2020;69:545-50.

19 Geleris J, Sun Y, Platt J, et al. Observational study of hydroxychloroquine in hospitalized patients with Covid-19. $N$ Engl J Med 2020;382:2411-8.

20 Rosenberg ES, Dufort EM, Udo T, et al. Association of treatment with hydroxychloroquine or azithromycin with in-hospital mortality in patients with COVID-19 in New York state. JAMA 2020;323:2493-10.

21 Watson J, Whiting PF, Brush JE. Interpreting a covid-19 test result. BMJ 2020;369:m1808

22 Heath Research Authority. Uk policy framework for health and social care research definition of research, 2017. Available: http://www. hra-decisiontools.org.uk/research/docs/DefiningResearchTable Oct2017-1.pdf 